\title{
PROTAGONISMO JUVENIL EM ENSINO DE INGLÊS: LEITURA CRÍTICA DE CANAL DO YOUTUBE
}

\author{
Ludmila Ameno Ribeiro $^{1}$
}

\begin{abstract}
Resumo: O objetivo deste artigo é mostrar uma contribuição para o fomento da leitura crítica nas aulas de inglês, através do protagonismo juvenil exercido em um canal do Youtube. Sabendo que o mundo virtual é o espaço que o jovem sociabiliza, é preciso procurar adotar na sala de aula propostas que permeiem a participação social crítica do jovem em formação, para que esse possa exercer plenamente seu protagonismo. Assim, mostramos como a proposta de um canal no Youtube instiga o posicionamento do jovem, em outras palavras, o letramento crítico em exercício (MATTOS, 2012; MORGAN; MONTE-MÓR, 2014). Em suma, pensando nas experiências de leitura contemporânea, interação dos jovens e desenvolvimento do letramento crítico, evidenciamos como o professor de inglês pode escolher insumos na mídia para fazer um trabalho de letramento crítico. $\mathrm{O}$ corpus analisado foi um canal no Youtube, que divulga a série nomeada How Kids react to pop stars... (Como os meninos e meninas reagem às estrelas pop..), como exemplo de instância de leitura crítica para ser adaptada para a aula de língua estrangeira. No vídeo os participantes são levados a interagirem, a exercerem sua opiniáo, agência e a se posicionarem. Através desse método, levantamos os seguintes aspectos: elegemos este vídeo como exemplo de uma possível atividade em sala de aula parecida com a do vídeo para o desenvolvimento do letramento crítico; buscamos meios de auxiliar o aluno a exercer a agência em seu posicionamento; incentivamos o protagonismo no século XXI e papel de agência do aluno; entendemos esta como uma possibilidade de desenvolver o letramento critico por meio do protagonismo juvenil, assim como o desenvolvimento das competências comunicativas em língua inglesa (compreensão, oralidade, escrita, leitura e aspectos léxico-sistêmico).
\end{abstract}

Palavras-chave: Leitura Crítica. Protagonismo juvenil. Ensino de Inglês.

1 Doutoranda em Estudos de Linguagens pelo Programa de Estudos de Linguagens, CEFET-MG. Mestra em Estudos de Linguagens, CEFET-MG. Especialista em Ensino e Aprendizagem de Inglês pela Universidade Federal de Minas Gerais, UFMG. Graduada em Letras licenciatura plena Português/Inglês, Centro Universitário de Belo Horizonte, UNI-BH. Professora de Inglês desde 2008. 


\title{
YOUTH PROTAGONISM IN ENGLISH TEACHING: CRITICAL READING OF A YOUTUBE CHANNEL
}

\begin{abstract}
This article objective is to show a contribution to the promotion of critical reading in the English class, through the youth role played on a YouTube channel. Knowing that the virtual world is the space that young people socialize, it is necessary to try to adopt in the classroom proposals that permeate the critical social participation of young people in training, so that they can fully exercise their role. Thus, we show how the proposal for a YouTube channel instigates the positioning of young people, in other words, critical literacy in practice (MATTOS, 2012;MORGAN; MONTEMÓR, 2014). In short, thinking about the experiences of contemporary reading, the interaction of young people and the development of critical literacy, we show how the English teacher can choose inputs in the media to do critical literacy work. The analyzed corpus was a channel on Youtube, which disseminates the series called: How Kids react to pop stars, as an example of an instance of critical reading to be adapted for the foreign language class. In the video, participants are encouraged to interact, exercise their opinion, agency and position themselves. Through the method chosen in this work, we raised the following aspects: we chose this video as an example of a possible classroom activity similar to that of the video for the development of critical literacy; we look for ways to help the student to exercise the agency in its positioning; we encourage protagonism in the 21 st century and the role of student agency; we understand this as a possibility to develop critical literacy through youth protagonism, as well as the development of communicative skills in English (comprehension, orality, writing, reading and lexical-systemic aspects).
\end{abstract}

Keywords: Critical Literacy. Youth leadership. Teaching English.

\section{INTRODUÇÃO}

Aprender inglês no ensino básico é um direito assegurado pela Lei de Diretrizes e Bases da Educação Nacional (BRASIL, 1996) e reafirmado pela Base Nacional Curricular Comum (BRASIL, 2019). Além disso, as dimensões do ensino de inglês como língua estrangeira moderna vão além de ensinar somente as competências comunicativas e linguísticas, uma vez que o mundo atual requer que os alunos saibam ler, interagir e produzir de forma multimodal e em várias práticas de letramentos (COPE; KALANTZIS, 2008). Com isso, é recomendado pelos Parâmetros Curriculares Nacionais. PCN+ (BRASIL, 2012) e pelas Orientações Curriculares para o Ensino Médio, OCEM (BRASIL, 2008) um trabalho sistemático que vise que o professor adote atividades de práticas de letramento na sala de aula de línguas, objetivando propiciar um trabalho reflexivo, buscando contribuir para a formação crítica do aluno/leitor.

Neste trabalho visamos fomentar uma contribuição para a prática docente do professor de inglês como língua estrangeira. Assim, propomos que a inserção de um canal do Youtube pode corroborar para o desenvolvimento do letramento crítico dos estudantes, ao mesmo tempo, que promove a sociabilidade juvenil. Por meio de insumos da Teoria de Letramento Crítico e dos documentos norteadores para o ensino de línguas, mostraremos como os anúncios de perfumes tendem a representar os gêneros. 
A priori, é necessário tratar sobre o conceito de Letramento desenvolvido por Soares (1998) que, nas palavras da autora: "Letramento não é pura e simplesmente um conjunto de habilidades individuais; é o conjunto de práticas sociais ligadas à leitura e à escrita em que os indivíduos se envolvem em seu contexto social (SOARES, 1998, p. 72)". Ou seja, Letramento significa a ação do uso e das práticas sociais em que perpassam a leitura e a escrita nos vários contextos de nossas vidas.

Promover os multiletramentos dos estudantes implica em promover espaços para que os estudantes aprendam a construir sentido, a ler e a interagir utilizando as mídias digitais em diferentes contextos. Assim, o professor deve focar em trabalhar os diversos gêneros textuais e multimodais, permear o trabalho em equipe, visar a aprendizagem participativa e colaborativa (KALANTZIS; COPE, 2012).

\section{JUVENTUDE NO BRASIL}

$\mathrm{Na}$ atualidade, com todas as transformaçóes trazidas pelas tecnologias digitais, Oswald e Rocha (2013) afirmam que é preciso considerar o meio virtual como mediador de atividades de aprendizagem, leitura, escrita e de sociabilização dos jovens. À vista disso, o discurso e tradicionalismo de valorizar o livro como suporte exclusivo de leitura e aprendizagem perde sua força. Já que, como Oswald e Rocha (op. cit.) argumentam, as tecnologias digitais ampliaram as formas de ler e interagir com o mundo. Além disso, como aponta Jenkins (2009), estamos inseridos na cultura da convergência, em que os consumidores de mídias interagem e participam ativamente, permitindo que busquem novas informaçóes e novos conteúdos de acordo com suas escolhas e necessidades pessoais. Segundo Jenkins (op. cit.), a cultura participativa colabora para que o indivíduo desenvolva sua autonomia e conscientize sobre seu papel social. Portanto, nesse novo cenário, o professor deve buscar meios de adotar em sua prática pedagógica formas de interação que contribuam para a autonomia, ética, criticismo, conscientização crítica e leitura de mundo do jovem aluno (FREIRE, 1994).

Para isso é preciso entender que no Brasil, segundo Passos (2007), as formas de vivenciar a juventude variam de acordo com a camada social que um está inserido. Além de que, no Brasil, para alguns a jovens essa fase da vida é prolongada até a idade adulta. Assim, de forma desigual, permeia que uns arquitetem seus planos por meio da educação formal, tenham espaço para sociabilizar e até mesmo para serem rebeldes nessa fase. Em contrapartida, outros menos favorecidos, deixam os estudos para trabalhar e arcar com as próprias despesas, já que devem auxiliar a família, e consequentemente, exercem a identidade adulta. É também levantado que há jovens que não têm espaço para a socialização, fazendo com que as ruas sejam o ambiente de sociabilizaçấo, e desse modo, são vistos como marginais. A autora (op. cit.) ainda versa sobre a forma como a escola e a literatura são meios didáticos com o intuito de ajudar as famílias a educar as crianças e os jovens para ingressarem a vida adulta (PASSOS, 2007).

Em consonância com a autora, Abramovay e Castro (2015) acreditam que o conceito de juventude no Brasil tem de ser pluralizado, assim teremos várias 
“juventudes”, já que a forma de ser jovem de cada cidadão no país dependerá do poder aquisitivo das famílias desses jovens. Acrescentam ainda que, a juventude é uma construção social em um dado momento histórico, que depende do meio e status financeiro para se afirmar. Segundo elas, os jovens da atualidade permanecem mais nessa fase da vida, já que a inserção no mercado de trabalho tem sido cada vez mais dificultada e a busca pela educaçáo formal estendida. As autoras (op. cit.) apontam vários obstáculos que dificultam o exercício pleno dos direitos juvenis, tais como: não reconhecer a identidade do ser jovem (ou ele é infantilizado, ou forçado a ser adulto); discriminação e estereótipos do jovem devido a sua classe social; náo levar em conta os direitos dos adolescentes de serem jovens e poderem exercer plenamente o direito de obter uma educação formal, falta de espaço para socialização e direito para se expressar em sua própria linguagem (ABRAMOVAY; CASTRO, 2015).

Há ainda problemas mais graves que assolam a juventude, como a violência e a marginalidade, que muitas vezes são fomentadas pelo consumismo, e pela cultura de violência e ostentação. Os jovens em específico podem ingressar na marginalidade quando instigados a buscar referências e autoafirmação através do consumo de mercadorias e bens para sentirem-se satisfeitos consigo mesmos e admirados pelos amigos (ABRAMOVAY; CASTRO, 2015).

Na visão de Souza e Silva (2006) os jovens são influenciados e influenciam também. Independentemente de sua classe social e poder aquisitivo, os jovens modificam a forma como suas famílias consomem. Sendo assim, são alvos das mídias com novidades, acabam por serem responsáveis por movimentarem bilhóes na economia brasileira. Todavia, por estar em formaçãa, o jovem consumidor se torna vulnerável aos símbolos que deseja consumir, e aprende a exercer sua identidade através dos produtos que deseja comprar. A exerção identitária através da aquisição de produtos é um dos problemas causados pelo excesso de consumo na juventude, ou seja, o jovem aprende que ele é o que pode comprar, e quando náo pode pagar por produtos autênticos aceita o falsificado. Dessa maneira, o jovem pode ter a formação de sua personalidade afetada, podendo se tonar dependente das estratégias de marketing, e se tornar um consumidor acrítico (SOUZA; SILVA, 2006).

\subsection{PRÁTICAS DE MULTILETRAMENTOS, CULTURA PARTICIPATIVA E SOCIABILIDADE JUVENIL}

Visando promover um trabalho de leitura crítica e participativa, é importante que o docente foque em desconstruir ideias amplamente promovidas sobre a forma de como o jovem interage, lê o mundo, lida com o consumo e consigo mesmo. Em vista disso, é preciso que o professor busque meios de contribuir para que o aluno reflita sobre sua identidade, seu meio, sua realidade e que fique atento para rejeitar imposiçóes (FREIRE, 1994). A saber:

A percepção ingênua da realidade, da qual resultava uma postura fatalistacondicionada pela própria realidade- cede seu lugar a uma percepção capaz de se ver. E se o homem é capaz de perceber-se, enquanto percebe uma realidade 
que lhe parecia "em si" inexorável, é capaz de objetivá-la, descobrindo sua presença criadora e potencialmente transformadora desta mesma realidade. O fatalismo diante da realidade, característico da percepção distorcida, cede seu lugar à esperança. Uma esperança crítica que move os homens para a transformação (FREIRE, 1994, p. 27).

O educador crítico deve incumbir-se de conscientizar o jovem sobre seu papel de sujeito transformador de sua própria realidade, instigando-o a perceber seu valor, trabalhando a autoestima desse jovem e ressaltando seus direitos como cidadáo (FREIRE, 1994). E há muitos caminhos para o professor inserir em sua prática pedagógica formas diversificadas de leitura contemporânea de mundo, visando desconstruir a tradição escolar de que somente através do livro e da literatura canônica amplia-se a visão de mundo do aluno (OSWALD; ROCHA, 2013).

Com a cultura participativa no espaço virtual e com os fanfictions, Magnoni e Miranda (2013) afirmam que o jovem leitor busca entretenimento através de registrar sua opinião sobre a obra lida, interage, participa, acrescenta novas ideias à narrativa. Assim, a tecnologia e a internet facilitaram a construção que um fã produz de uma obra, ou seja, propiciou um novo paradigma em que o leitor não somente consome a obra, mas é incentivado a exercer a sua criatividade para dar novos sentidos ao que foi lido. Para os autores (op. cit.) o meio virtual é buscado por crianças e adolescentes de várias esferas sociais, até mesmo aqueles com menos recursos financeiros e menos acesso, para exporem a releitura que fizeram da obra. Mesmo que para eles tudo não passe de uma brincadeira e busca por entretenimento, o leitor acaba por participar das práticas de letramento por meio da produção na web (KALANTZIS; COPE, 2012). Portanto, é essencial que os educadores reflitam sobre a forma como trabalham a leitura e escrita na sala de aula, pois, o meio virtual permeia a participaçáo do leitor nesse ambiente através da leitura, pesquisa, escrita e colaboração participativa (MAGNONI; MIRANDA, 2013).

Para Almeida (2019) o mundo digital fomenta a democratização do acesso e compartilhamento das leituras literárias, assim como, permite a divulgação através de fóruns e dos canais destinados à indicação literária (por meio dos booktubers), indicando-as ao público jovem. Dessa forma, segundo a autora (op. cit.), por tratar de questóes ligadas ao universo juvenil, e consequentemente, da formaçáo identitária do leitor, é essencial que, professores, a escola e os canais de recomendação literária tenham ética na recomendação de livros. Pois, muitos livros propagam estereótipos de gênero, racial e podem instigar comportamento sexista e racistas em detrimento de certos grupos. Assim, o papel da escola na formação do jovem leitor é a de ampliar a diversidade dos repertórios literários, auxiliar o leitor a ler criticamente e a buscar obras de maior complexidade. Além disso, a literatura por meio da catarse permeia a conscientização e até a transformação de convicçôes e libertação dos sentimentos que causam mal estar no leitor (ALMEIDA, 2019).

Há muitas formas de diferentes naturezas, independente do suporte, para se trabalhar os multiletramentos em sala de aula (KALANTZIS; COPE, 2012). Desse modo, seja por meio de: vídeos, notícias de jornal, sites, artigo científico, propagandas, receita culinária, música, poesia, narrativas, contos, etc; (sendo esses 
digitais ou náo). Quando utilizados para o desenvolvimento dos multiletramentos, esses gêneros textuais instigam o jovem a perceber, a ler e a interagir no mundo buscando adequar às práticas de letramentos (KALANTZIS; COPE, 2012).

Para entender os conceitos de letramentos e multiletramentos, esclareceremos o termo de letramento no singular que, segundo Rojo (2009), refere-se às:

[...] práticas sociais de letramento que exercemos nos diferentes contextos de nossas vidas vão constituindo nossos níveis de alfabetismo ou de desenvolvimento de leitura e de escrita; dentre elas, as práticas escolares. Mas não exclusivamente. É possível ser não escolarizado e analfabeto, mas participar das práticas de letramento, sendo, assim, letrado de uma certa maneira. $\mathrm{O}$ termo letramento busca recobrir os usos e práticas sociais de linguagem que envolvem a escrita de uma ou de outra maneira, sejam eles valorizados, locais ou globais, recobrindo contextos sociais diversos (família, igreja, trabalho, mídias, escola, etc.), numa perspectiva sociológica, antropológica e sociocultural (ROJO, p. 11, 2009).

A autora (op. cit.) acrescenta que, a escola é o local que viabiliza formalmente a participação do aluno nas várias práticas de letramentos por meio da leitura, escrita e através do diálogo com a cultura canônica e popular (ROJO, 2009). Ademais, trabalhar os multiletramentos na escola implica em: compreender e produzir sentidos através das linguagens (corporal, verbal, não-verbal, musical, etc.), em diferentes contextos e diversas línguas (focando na fala em diferentes modos, leitura, escrita e em ouvir). Além de conhecer as variáveis formas de letramentos, saber compreender e produzir os vários gêneros textuais (em diversas mídias e adequados a cada contexto), é preciso que o aprendiz saiba utilizar a língua exercendo seu protagonismo, ética e criticidade (ROJO, 2009).

Para o desenvolvimento de multiletramentos, de forma crítica e multimodal constatamos meios diversificados de se trabalhar os gêneros textuais canônicos, tais como, a poesia. Neves (2017), por exemplo, sugere os slams. como uma poesia oral e performática. Segundo ela, os slams consistem numa intervenção artística e teatral, intertextual, cuja temática trata de questôes de gênero, racismo, desigualdade social, violência, que permeiam que um grupo oprimido resista e construa a sua visibiliadade contra os discursos hegemônicos. Assim, o engajamento crítico e empoderamento são fomentados através da contestação poética e batalha artística, e são meios de levar a poesia, literatura de grupos minoritários e periféricos para terem sua contestaçáo inserida no contexto escolar como uma prática de letramento (NEVES, 2017).

Há também outras formas de se fomentar os multiletramentos de forma participativa e que os jovens já estão habituados. Como por exemplo, espaços digitais como a plataforma Youtube, como um modelo de mídia que instiga a cultura participativa. Sobre o conceito cultura participativa, Jenkins (2009) caracteriza como a forma que o consumidor midiático deixa de ser um receptor passivo e passa a interagir com a mídia. No caso do Youtube, o consumidor pode: comentar, criticar, produzir conteúdos parecidos, novos conteúdos, ou seja, há vários jeitos de incentivar a participaçáo colaborativa, já que o consumidor pode se apropriar de 
elementos da narrativa que é fã e que admira, para construir sua própria versão da história (JENKINS, 2009).

O mundo virtual como o espaço que o jovem lê, interage, aprende, produz e sociabiliza, deve ser o ambiente para o desenvolvimento de conhecimentos essenciais para o mercado de trabalho e participação social crítica do jovem em exercício de sua cidadania (BROOKS-YOUNG, 2010). Segundo a autora (op. cit.), os alunos devem ser motivados a engajarem criticamente por meio das ferramentas digitais, (mas isso não implica que o professor somente peça digitalmente as habituais tarefas feitas a mão). Desse modo, os professores devem utilizar a tecnologia para auxiliar no processo de comunicação, produtividade e criatividade, isto é, atividades que estimulem o aluno a resolver problemas reais (que sejam parte do meio que estamos inseridos), de forma colaborativa, criativa e crítica. E ainda acrescentado que, por estarem constantemente navegando na web e participando das redes sociais, fazendo downloads, jogando, participando de fóruns e chats, comentando na web, $e t c$; é essencial que o educador busque tratar sobre a ética no mundo virtual, direitos autorais, política de privacidade, segurança na web, cyber-bullying, plágio, e sobre o que pode ser compartilhado ou não no mundo virtual. Dessa forma, para que o meio virtual possibilite a aprendizagem como uma forma de exercício identitário e da autonomia do aprendiz, é essencial ensinar a preservação da imagem e o respeito a todos no mundo virtual (BROOKS-YOUNG, 2010).

\section{DESENVOLVIMENTO DE LEITURA E LETRAMENTO CRÍTICO}

Para se definir letramento crítico é importante compreender o conceito de letramento, que desenvolvido por Soares (1998) implica saber: "Letramento não é pura e simplesmente um conjunto de habilidades individuais; é o conjunto de práticas sociais ligadas à leitura e à escrita em que os indivíduos se envolvem em seu contexto social (SOARES, 1998, p. 72)". Ou seja, Letramento significa a ação do uso e das práticas sociais em que perpassam a leitura e a escrita nos vários contextos de nossas vidas.

Em relação ao conceito de Letramento Crítico, Mattos (2012) entende como a forma de conceder ao leitor-autor níveis mais profundos de compreensão, instigando-o ao questionamento, reflexão e diálogo sobre o texto, modificando assim, a relação de poder entre autor e leitor. Segundo a autora (op. cit.) o letramento crítico visa a promover o pensamento crítico para o desenvolvimento da educação voltada para o exercício futuro da cidadania. Dessa forma, o letramento crítico pode ser adotado por professores e pesquisadores que objetivam modificar os conceitos ideológicos que são lidos como "certezas culturais", já que, para Mattos (2014) alguns grupos sociais vem controlando as ideologias, instituições e práticas para manterem status e controle.

Para Morgan (1997) a educação crítica foca em auxiliar o aprendiz a agir de forma crítica, a ler os textos e analisar os discursos que esses vinculam. Para isso, é preciso que o professor faça perguntas que vão além da compreensão textual sobre o que está explícito no texto, já que, segundo a autora (op. cit.), muitas vezes 
há intenções que veiculam relaçôes de poder. Para Mattos (2012) as práticas de letramento crítico na nossa sociedade concentram-se nas diferenças de etnia, gênero, orientação sexual, classe social, etc; e a forma como essas diferenças são focadas, nos mostram que nada é neutro, tudo é construído na prática discursiva e no contexto.

$\mathrm{Na}$ mesma linha Morgan e Monte Mór (2014) afirmam que a garantia de que todos nascidos são cidadãos intitulados de direitos e responsabilidades, não é o suficiente para resguardar que todos os brasileiros serão oportunizados da mesma forma. Assim, para transformar esse cenário é preciso um trabalho que permeie o entendimento das desigualdades que assolam nosso país. É também necessário uma educação que vislumbre a cidadania, que para eles (op. cit.) corresponde a dar espaços para que esses cidadáos estejam aptos a participarem da democracia para deliberarem, debaterem, discutirem e participarem de assuntos de interesse público em esferas além das governamentais. Já que a cidadania crítica/engajada também pode ser alcançada por meio de conhecimentos, atos de dissenso, discordância política e da mobilização provisória das alianças (eles contra nós). Em outras palavras, a cidadania crítica/engajada é um modelo que faz a diferença, permitindo uma participação social crítica e escolhas em que o indivíduo percebe que suas escolhas vão além do individual. E isso é possibilitado através do diálogo entre as várias vozes, que concordam e discordam em prol de objetivos semelhantes (MORGAN; MONTE MÓR, 2014).

Puechner (2017) mostra em sua pesquisa que a prática de letramento crítico deve ir além de simplesmente criticar e teorizar sobre as possibilidades de transformação, mas sim dar ao professor estratégias concretas para se ensinar a cultura do poder. Outro problema que os professores enfrentam ao abordarem o letramento crítico em sua a prática, é sobre a questão de criar um currículo que prepare o aluno para ingressar em uma universidade e obter sucesso acadêmico, ou optar por ensinar de forma crítica e transformativa. Para a autora (op. cit.) a prática deve ser híbrida (voltada para o sucesso acadêmico e engajadora/crítica ao mesmo tempo), assim os professores devem: usa as ferramentas disponíveis para planejar uma prática que envolva objetivos críticos/transformativos e que permita ensinar buscando equidade e justiça social; encontrar formas de falar sobre status sócio-economico, etnia, gênero e sexualidade, que inclua outras identidades que geralmente são marginalizadas, independente das estratégias de ensino que estão sendo usadas; ao mesmo tempo, deve ser real com os alunos sobre as desigualdades curriculares que eles possivelmente enfrentarão (PUECHNER, 2017).

Ensinar a língua estrangeira pautada no letramento crítico foca em ensinar o idioma com a finalidade de promover reflexão, ação e mudanças, através da percepção ideológica das relaçóes de poder dominantes embutidas em determinado contexto histórico-social, e que de alguma forma contribuem para a relação de desigualdade e injustiça (MATTOS, 2014).

Darvin e Norton (2017) afirmam que os alunos trazem para a sala de aula diferentes bagagens culturais e o desafio dos educadores da atualidade é reimaginar a prática pedagógica que consiga atingir a diversidade, a mobilidade digital e a 
transculturalidade mundial, enquanto aborda as questóes contraditórias trazidas pelo mecanismo ideológico que reproduz as desigualdades. Segundo os autores (op. cit.) precisamos de uma pedagogia crítica que repense e ressignifique os conhecimentos e os letramentos que tradicionalmente têm sido valorizados no meio escolar. Assim, os estudantes devem aprender a reconhecer e a valorizar os diferentes tipos de conhecimentos, culturas e as várias formas de modalidades e linguagens que propagam inequidades (DARVIN; NORTON, 2017).

Dias (2012) defende a integração dos gêneros digitais associados às práticas pedagógicas para desenvolver os letramentos, já que por meio das ferramentas digitais, o aluno brasileiro pode desenvolver as habilidades de escrever, ler, compreender e falar o inglês. Assim, a autora (op. cit) ao apresentar os gêneros digitais e multimodalidade, expóe o conceito de atitude agentiva, que faz referência à forma como o papel do usuário de tecnologia não é de sujeito passivo, já que permeia a criaçáo, edição, escrever comentários, colaborar e produzir conteúdos online, fazendo com que, essa interação com os diferentes gêneros digitais promovam cada vez mais a inserção do aluno em vários contextos sociais. Dessa forma, o espaço virtual e multimodal com suas possibilidades de acesso aos hiperlinks transformam o modo como as habilidades de leitura e compreensão podem ser acessadas, permitem abordar os diferentes gêneros textuais escritos e orais, para que os alunos de educação básica à superior compreendam cada vez mais, as diferentes modalidades da língua e saibam usá-las de acordo com a função social de cada uma (DIAS, 2012).

A prática pedagógica embasada no letramento crítico, segundo Dias (2012), instiga os professores a trabalharem de forma construtiva, buscando otimizar o tempo em sala de aula. Para isso, é necessário que a aprendizagem promova o poder de criação, autonomia do aluno, atividades que proponham o trabalho colaborativo, e instiguem o pensamento crítico, de modo a incentivar o aprendiz a exercer sua cidadania futuramente.

Por meio da aprendizagem participativa e colaborativa, os aprendizes passam a agir como autores e a refletirem sobre a própria aprendizagem, fator táo essencial para o trabalho da autonomia do aluno. Sendo assim, para permear a participaçáo social do aluno é preciso um trabalho que ensine a interagir com os vários gêneros textuais híbridos e a produzir sentido usando as mídias digitais em diferentes contextos, ou seja, é preciso que a prática pedagógica promova o multiletramento do aprendiz (KALANTZIS; COPE, 2012). Os autores sugerem uma transformação no paradigma educacional, além de visualizarem as tecnologias como recursos em potencial, que podem vir a ser excelentes mediadores para o processo de aprendizagem.

O ambiente de aprendizagem com vídeos, músicas, atividades de escrita, textos multimodais, jogos e outros recursos possibilitam input autêntico em língua estrangeira, para auxiliar o aprendiz por meio da tecnologia, a construir condiçóes de recriar a aprendizagem (ZHAO, 2005). O autor (op.cit) afirma que a funçâo da tecnologia depende do contexto em que está inserida, e aos educadores cabe o papel 
de perceber as possibilidades das tecnologias digitais e adotá-las de acordo com as necessidades dos aprendizes.

Pensando no jovem e suas várias formas de sociabilizar, direcionamos este artigo para mostrar as possibilidades de como o professor de língua estrangeira pode utilizar um canal do Youtube, para realizar uma atividade que seja relevante para seu aluno, ao mesmo tempo que, colabore para o desenvolvimento do letramento crítico e a leitura de mundo.

\section{PROPOSTA DE USO DE UM CANAL DE YOUTUBE PARA A LEITURA CRÍTICA}

Este trabalho visa focar na sociabilização da geração atual como participativa, que exercita plenamente seus direitos, com identidade e opiniáo própria, que vivem em uma época de transições de todos os tipos (cultua de ostentação, mudanças econômicas, de consumo e tecnológicas, moral e social) (ABRAMOVAY; CASTRO, 2015). Busca também, promover um input autêntico em língua estrangeira para o desenvolvimento da leitura crítica (ZHAO, 2005; DIAS, 2012). Assim, escolhemos como corpus de análise deste trabalho um canal do Youtube, que divulga a série nomeada How Kids react to pop stars... (Como os meninos reagem às estrelas pop..), como exemplo de instância de leitura crítica. Em cada episódio da série os diretores Benny e Rafi, conhecidos como "The Fine Brothers" escolhem um grupo de meninos e meninas, de idades entre 6 a 15 anos, e resgatam diferentes situaçóes que permitem que os participantes expressem sua reação, opinião e ponto de vista. Pois, o vídeo media uma atividade que oportuniza os alunos a opinarem e construírem sua visão de concordância e ou discordância (MORGAN; MONTE MOR, 2014).

A plataforma Youtube foi escolhida já que sabemos que cada vez mais o jovem participa, colabora e interage por meio das mídias digitais. Sendo assim, parece essencial inserir as ferramentas digitais na sala de aula para ajudar o aluno a perceber a noçáo de autoria no meio digital, já que a sociabilização no meio digital colabora para o processo de letramento. Logo, o contexto escolar náo é o único meio para fomentar o desenvolvimento dos letramentos por meio da escrita, leitura, fala, e qualquer gênero textual que um se depare (MAGNONI; MIRANDA, 2013; KALANTZIS; COPE, 2012).

O episódio escolhido é nomeado: How Kids react to Pop Stars: The Beatles (Como os meninos e meninas reagem às estrelas pop: Os Beatles), e conta com a participaçáo de 5 meninos e 6 meninas, de 6 a 14 anos. As entrevistas com os participantes são individuais e os mesmos sáo observados enquanto assistem aos videoclipes dos Beatles e expressam sua impressão e opiniáo sobre o que assistem. $\mathrm{O}$ vídeo é dividido em dois momentos, primeiro momento há as impressôes dos participantes (3:15 de tempo); segundo momento, os questionamentos que os autores fazem aos participantes (5:40 de tempo).

O layout inicial do vídeo é um quadro negro remetendo ao contexto da sala de aula, assim como o layout das entrevistas individuais, que é caracterizado da 
seguinte forma: para as meninas o pano de fundo das entrevistas lembra uma sala de aula com papel de parede lilás, quadro com coraçóes, flores, e magnéticos para deixarem o espaço bem feminino; em contrapartida, para os meninos o cenário de sala de aula tem como pano de fundo uma parede azul, uma estante amarela com livros e um quadro de avisos de cortiça.

Figura 1 - Tag do vídeo no canal Youtube

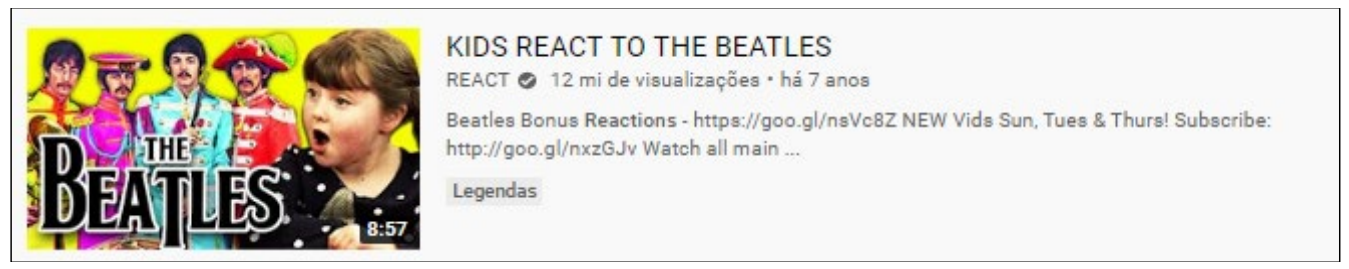

Fonte: https://www.youtube.com/watch?v=_M9US-cXJMo

Ao analisar o episódio, destacamos que, o vídeo exemplifica a cultura de convergência, como cunhado por Jenkins (2009), mostrando as transformaçóes culturais e sociais ocorridas no cenário musical da época de quando os Beatles começaram a fazer sucesso até o momento que se separaram. Durante as entrevistas nota-se que os participantes usam as referências culturais presentes para melhor explicarem e contextualizarem o passado.

Ao analisarmos as impressóes iniciais e respostas dos participantes diante às perguntas feitas pelo entrevistador/professor percebemos que: no decorrer de seus posicionamentos os participantes observaram, descreveram suas emoçóes, sentimentos, até se posicionarem sobre a banda, gênero musical, momento cultural passado e momento cultural presente. Em outras palavras, o episódio ilustra o letramento crítico em exercício. Assim, pensando na sala de aula de língua estrangeira, o professor pode planejar atividades como essa, que foquem no desenvolvimento das competências linguísticas do aluno, no caso da língua inglesa, planejando uma atividade comunicativa que trabalhe: compreensão, oralidade, escrita, leitura, léxico-sistêmico. E simultaneamente, tratar das questóes críticas, voltadas para o protagonismo juvenil, por meio da reflexão e diálogo (PUECHNER, 2017; MATTOS, 2014; OCEM, 2008).

Levantamos que todos os participantes, com exceção do participante mais jovem (Maxim, um menino de 6 anos) sabiam quem eram os Beatles; alegam terem ouvido os Beatles porque seus pais eram fâs, seus professores gostavam e (na continuaçáo do mesmo episódio); alegaram que ouviram pela primeira vez as músicas dos Beatles em propagandas e em desenhos infantis.

Observamos no corpus analisado que as crianças participantes manifestam o desgostar e o gostar com mais facilidade do que os adolescentes. Sendo assim, ressaltamos a preocupação em desagradar, e insegurança em opinar sobre o vídeo e contrariar a opinião da maioria das pessoas está presente em alguns comentários dos adolescentes, já que os pais e professores surgiram na fala dos participantes como făs 
de Beatles. Dessa forma, em consonância com o que afirma Souza e Silva (2016), observamos que nessa fase da vida, os jovens apresentam uma dificuldade maior para expressar a própria linguagem, já que sáo pressionados a exercerem plenamente sua identidade, desde que essa seja referenciada pelo meio. Para ilustrar essa situação destacamos os seguintes comentários: "Não se pode não gostar de Beatles, caso contrário você pode ser assassinado!" (Seth, 14 anos de idade); "Conheço os Beatles desde a barriga da minha mãe!" (Elle, 11 anos de idade); "Meu pai falou que é uma banda genial! (Morgan, 8 anos de idade)."; "Minha mãe ama os Beatles!" (Olívia, 12 anos).

Analisando esses comentários percebemos que os jovens participantes tenderam a moldar seus gostos e ideias sobre o que é bom por meio da influência de outras pessoas. Segundo Souza e Silva (2006), o adolescente pode ser caracterizado como inseguro, dependente da opiniáo e da aprovaçáo de seu meio social. Contudo, enfatizamos que o comentário de teor irônico do jovem Seth, demonstra que ele analisa a forma discursiva de como certos gostos musicais sáo quase que impostos, não cabendo discordar. Assim, ao permear espaço para o questionamento das relaçóes de poder impostas estamos ajudando o aluno a refletir criticamente e de forma ética, para que ele encontre sua própria voz (MORGAN, 1997).

Constatamos que, durante a maior parte das entrevistas, os participantes se posicionaram e exerceram seu protagonismo agindo criticamente. Desse jeito, por meio de comentários que demonstraram como perceberam o passado, estranharam os estilos de roupas e cabelos. Eles também associaram a influência de elementos como roupa, música, estilo de cabelo, em ícones do presente como Justin Bieber, One Direction e Cold Play. Portanto, constatamos que por meio desse tipo de percepção os entrevistados notam a reapropriaçáo e a releitura de modos antigos nas produçóes atuais (JENKINS, 2009). Além de ampliarem o domínio discursivo por meio de uma prática de letramento conduzida de forma reflexiva, que possibilita o diálogo (MATTOS, 2012; MATTOS, 2014).

Atestamos que as músicas mais famosas como I wanna hold your hand, e Hey Jude, receberam comentários positivos, justamente por serem músicas já conhecidas pela maioria dos participantes. Porém, a música The Warrius, uma canção menos popular, foi recebida com estranhamento por todos. Ao serem questionados sobre os Beatles serem melhores ou piores que a música atual, metade dos participantes acreditam serem muito melhores e a outra metade pior. Comentários como: "Os Beatles são melhores porque a música hoje é tão horrível! (Darius, 13 anos de idade)"; "Todos vão me odiar pelo que vou dizer. Eles até podem ser melhores que a música atual, mas eu prefiro a música atual (Bryson, 14 anos de idade)"; "Justin Bieber é melhor! (Paris, 12 anos de idade)". Os participantes concluíram que o sucesso dos Beatles na época e mesmo décadas depois do término da banda, deve-se ao fato de poderem tocar qualquer gênero musical, o que os torna mais comerciais e acessíveis, e ao mesmo tempo, clássicos.

A cultura participativa está presente na mente dos participantes do vídeo. Que ao comentarem sobre o término dos Beatles, logo assumem como os fấs reagiriam 
caso existissem as redes sociais naquela época. Assim, apontam o Twiter como o espaço para o questionamento, interação com outros fấs, socialização, lamentaçóes. Nessa fala dos participantes evidenciamos a possibilidade de uma reconfiguração das relaçóes que as mídias digitais exercem em suas vidas e como os usuários podem agir nesse cenário. Ou seja, se antes os fấs do passado só podiam lamentar em seus círculos de relacionamento e através de cartas, que talvez nem chegassem aos seus destinatários, e nem seriam respondidas. $\mathrm{Na}$ atualidade os fấs conseguem expor $\mathrm{o}$ que pensam sobre seus ídolos, interagem com outros fẫs no meio digital, e muitas vezes falam diretamente com seus ídolos. Por meio das ferramentas digitais os jovens participam mais ativamente da cultura de mídia. Assim, ele está se tornando capaz de assumir maior controle sobre o conteúdo midiático que consome e fazendo valer, mais enfaticamente, seu poder de escolha. $\mathrm{O}$ mesmo ocorre quando estabelece contato com outros usuários através de fóruns de discussão e comunidades virtuais, está experimentando novas formas de sociabilidade, marcadas por vínculos de pertencimento social diferentes daqueles experimentados tradicionalmente. (JENKINS, 2009; MAGNONI; MIRANDA, 2013).

Ao assistirem os registros em vídeos da reação dos fẫs, o que ficou conhecido como Beatlemania, os participantes ficaram surpresos, acharam engraçado, e perceberam que essa reação não é normal. Uma participante se espanta sobre o fato de a polícia empurrar os fãs, mantendo-os longe da banda. Em relação a Beatlemania, o entrevistador indagou os participantes se ele ou ela tinha ficado surpreso que há 50 anos atrás as pessoas agiam daquela forma pela banda, e os participantes disseram que tinham a ideia disso, mas esperava que as pessoas daquela geração agissem com mais maturidade e controle. Também perceberam que essa forma de agir dos fấs dos Beatles ainda influencia a reação dos fẫs por seus artistas e bandas favoritas. Porém, outros esperavam que essa reação descontrolada não fizesse parte do passado, já que esses meninos e meninas construíram a imagem de que as pessoas mais velhas (pais, avós, professores, etc.), não adotariam essa postura, entendida por eles como uma "reação desproporcional" e essa "loucura" e "estupidez" seria parte somente do tempo atual. Assim, essa pergunta do entrevistador promoveu outros questionamentos, como: "Você por acaso agia assim, vovô e vovó?"; "Os avós às vezes reclamam que nós somos loucos, mas percebo que eles eram loucos como nós somos!”. Por meio dessas opinióes concluímos que: as mídias digitais operam para fomentar a reflexão crítica de vários gêneros textuais de modo acessível e atual para se tratar de qualquer temática (COPE; KALANTZIS, 2008). Com esses comentários levantados, percebemos que esse tipo de atividade levada para a prática pedagógica auxilia o aluno a perceber as relaçôes de poder em determinado contexto históricosocial, e a forma como contribuem para estereótipos, preconceitos, desigualdade e injustiça em qualquer contexto. Dessa forma, o contexto da atividade serviu para os participantes refletirem sobre sua identidade, seu meio e sua realidade (FREIRE, 1994; MATTOS, 2014). 


\section{CONCLUSÓES}

Neste artigo tratamos do protagonismo juvenil presente num canal do Youtube, assim, obtemos as seguintes conclusôes:

A proposta do canal é interessante para ser adaptada para a aula de língua estrangeira, já que pode ser uma forma de auxiliar o desenvolvimento do letramento crítico e protagonismo dos jovens. No vídeo percebemos que os participantes são levados a interagirem, a exercerem sua opinião, agência e a se posicionarem. Igualmente, sugerimos que o professor, de forma crítica, reflexiva e ética, conduza seus alunos a se posicionarem.

Elegemos este vídeo como exemplo de uma sugestão para o professor, ou ainda sobre uma possível atividade em sala de aula parecida com a do vídeo para o desenvolvimento do letramento crítico. Uma vez que, no episódio escolhido notamos que o professor/entrevistador conduziu as entrevistas de modo a corroborar para que os participantes pudessem caminhar para se posicionarem. Desse modo, colaborando para que o jovem esteja apto a exercer a agência em seu posicionamento. Assim, por meio desse tipo de atividade, o professor incentiva o protagonismo no século XXI e papel de agência do aluno. Todavia, é necessário que isso seja feito através de planejamento, que instigue o processo reflexivo, para que o aluno construa seu ponto de vista e opiniáo sobre determinado assunto.

Ainda que o foco deste trabalho tenha sido o desenvolvimento de letramento crítico por meio do protagonismo juvenil, não estamos eliminando o desenvolvimento das competências comunicativas em língua inglesa (compreensão, oralidade, escrita, leitura e aspectos léxico-sistêmico), já que o vídeo é um tipo de input autêntico em língua estrangeira.

\section{REFERÊNCIAS}

ABRAMOVAY, M. e CASTRO, M. Ser jovem no brasil hoje: políticas e perfis da juventude brasileira. Cadernos Adenauer, Rio de Janeiro, v. 15, n. 1, p. 13-25, 2015.

ALMEIDA, Eliane Guimarães. Literatura juvenil sob a ótica de leitores adolescentes de meios populares. 2019. Tese (Doutorado em Educação: Conhecimento e Inclusão Social). Faculdade de Educação, Universidade Federal de Minas Gerais, Minas Gerais, 2019.

\section{BRASIL. MINISTÉRIO DA EDUCAÇÃO. Base Nacional Curricular Comum.}

Brasília: MEC/SEB/CNE, 2019. Disponível em: <http://basenacionalcomum.mec.gov. $\mathrm{br} />$ Acesso em: 28 de março de 2021.

BRASIL. Orientaçóes Curriculares para o Ensino Médio - Linguagens, Códigos e suas Tecnologias. Brasília: MEC/SEB, 2008. v. 1., p. 87-124.

BRASIL, MINISTÉRIO DA EDUCAÇÃO. Parâmetros Curriculares Nacionais. PCN +. Brasília, 2012. Disponível em: <http://portal.mec.gov.br/seb/arquivos/pdf/ linguagens02.pdf>. Acesso em: Abril de 2019. 
BRASIL. Presidência Da República Casa Civil. Lei n. 9.394, de 20 de dezembro de 1996. Estabelece as Diretrizes e Bases da Educação Nacional.

BROOKS-YOUNG, S. Teaching with tools kids really use: learning with web and mobile technologies. Estados Unidos: Corwin, 2010.

COPE, B.; KALANTZIS, M. Ubiquitous learning: an agenda for educational transformation. 2008. Disponível em: <http://www.networkedlearningconference.org.uk/ past/nlc2008/abstracts/PDFs/Cope_576-582.pdf> Acesso em junho de 2021.

DARVIN, R.; NORTON, B. Investing in new Literacies. In: Literacy Lives in Transcultural Times. Org: ZAIDI, R.; ROSWELL, J. New York: Routledge, 2017

DIAS, R. Gêneros digitais e multimodalidade: oportunidades online para a escrita e a produção oral em inglês no contexto da educação básica. In: DIAS, R.; DELL'ISOLA, R. L. P. (orgs.) Gêneros textuais: teoria e prática de ensino em LE. Campinas, SP: Mercado das Letras, 2012c. p. 295-315.

FREIRE, P. Educação e mudança. 20 ed. Rio de Janeiro: Paz e Terra, 1994.

KALANTZIS, M.; COPE, B. The work of learning and teaching literacies. In: Literacies. New York, Cambridge University Press, 2012. p. 1-13.

JEFFMAN, T. M. W. Booktubers. Performances e Conversaçóes em torno do livro e da leitura na comunidade booktube. 2017. Tese de Doutorado. (Programa de Pósgraduação em Comunicação). São Leopoldo: Unisinos, 2017. Disponível em: http://www. repositorio.jesuita.org.br/bitstream/handle/UNISINOS/6337/Tauana\%20Mariana\%20 Weinberg\%20Jeffman_.pdf?sequence=1 \&isAllowed=y Acesso em: junho de 2021

JENKINS, H. Cultura da Convergência. São Paulo: Aleph, 2009.

MAGNONI, A. F; MIRANDA, G. V. Novas formas de comunicação no século XXI: o fenômeno da cultura participativa. Conexão, Comunicaçáo e Cultura. UCS, Caxias do Sul. Vol. 12, n.23, jan/jun., 2013.

MATTOS, A.M.A. Education for citizenship: introducing Critical Literacy in the EFL Classroom. Nova Science Publisher: New York, 2012.

MATTOS, A.M.A. Construindo cidadania nas aulas de inglês: uma proposta para o Letramento Crítico. In: TAKAKI,N. H.; MACIEL, R. F. (Orgs.). Letramentos em terra de Paulo Freire. Campinas: Ed. Pontes, 2014.

MONTE MÓR, W: MORGAN, B. Entre a conformidade e a crítica. Desenvolvendo "ativismo" e cidadania ativa: pedagogias arriscadas? Interfaces Brasil/ Canada, v. 14, n.2, p. 16-35. Canoas: 2014.

MORGAN, W. Critical Literacy in the classroom: The art of the possible. New York: Routledge, 1997. 
NEVES, C.A. Slams- Letramentos Literários de Reexistência ao/no Mundo

Contemporâneo. Linha D’Água (online), v. 3º, n. 2, p. 92-112. São Paulo: 2017.

OSWALD, M. L.; ROCHA, S. L. A.; Sobre juventude e leitura na "idade mídia": implicaçôes para políticas e práticas curriculares. Educ. rev. [online]. 2013, n.47, p. 267283.

PASSOS, M. Literatura infantil e juvenil: uma reflexão sobre a construção da infância e da adolescência. In: Aparecida Paiva et al.. (Org.). Literatura: saberes em movimento. Belo Horizonte: Ceale; Autêntica, 2007, p. 1-184.

PUECHNER, S. D. Justice at the gate? Negotiating Tensions Between Critical Literacy and "Culture of power" Pedagogies. In: Journal of Adolescent \& Adult literacy, vol. 61, n. 3, p. 327-330. International Literacy Association: 2017.

ROJO, R. Letramentos múltiplos, escola e inclusão social. São Paulo: Parábola Editorial, 2009.

SOUZA, A. da S.; SILVA, C. P. da. O consumo na vida de adolescentes de diferentes condiçôes socioeconômicas: uma reflexão para o marketing no Brasil. Cadernos EBAPE. BR. v.4, n.1, mar. 2006.

SOARES, M. B. Letramento- Um tema em três gêneros. Belo Horizonte, CEALE/ Autêntica, 1998

ZHAO, Y. Technology and second language learning: promises and problems. In L. L. Parker (Org.), Technology-mediated learning environments for young English learners: Connections in and out of school (p. 167-205). Mahwah, NJ: Lawrence Erlbaum Associates, 2005. 